\title{
KAJIAN AWAL KESIAPAN GEDUNG BERTINGKAT DI JAKARTA TERHADAP BENCANA GEMPA BUMI
}

\section{PRELIMINARY STUDY ON THE READINESS OF MULTISTORY BUILDING IN JAKARTA AGAINTS EARTHQUAKE DISASTER}

\author{
Dr. Mulyo Harris Pradono ${ }^{1}$ \\ Dr. Odilia Rovara ${ }^{1}$ \\ Qoriatu Zahro S.Si., M.Sc. ${ }^{1}$
}

\begin{abstract}
In 2017, the Center for Disaster Risk Reduction (PTRRB) developed an assessment mothod for the readiness capacity of a multi-story building against the threat of earthquakes. Readiness capacity is the capacity of a building in terms of two aspects: facilities and soft skills. This method was then applied to 16 buildings of 377 high-rise buildings in DKI Jakarta. These 16 buildings were selected based on the overlay of the earthquake disaster (PGA) class against the vulnerability class. The expected results are the level of building readiness and recommendations to improve readiness.
\end{abstract}

Keywords: readiness, multistory building, earthquake

\begin{abstract}
Abstrak
Pada tahun 2017, Pusat Teknologi Reduksi Risiko Bencana (PTRRB) mengembangkan metode kajian terhadap kapasitas tindak suatu gedung bertingkat terhadap ancaman gempabumi. Kapasitas tindak adalah kapasitas suatu gedung ditinjau dari dua segi: fasilitas dan soft skill. Metode ini selanjutnya diaplikasikan pada 16 gedung dari 377 gedung bertingkat yang pernah dikaji cepat sebelumnya di DKI Jakarta. Ke-16 gedung ini dipilih berdasarkan overlay kelas ancaman bencana gempabumi (PGA) terhadap kelas kerentanan. Hasil yang diharapkan adalah tingkat kesiapan gedung dan rekomendasi untuk meningkatkan kesiapannya.
\end{abstract}

Kata kunci: kesiapan, gedung bertingkat, gempabumi

1 Pusat Teknologi Reduksi Risiko Bencana - Badan Pengkajian dan Penerapan Teknologi, Geostech, Gedung 820, Puspiptek, Serpong email: mulyo.harris@bppt.go.id

\section{PENDAHULUAN}

\subsection{Latar Belakang}

Secara geografis Indonesia terletak pada rangkaian cincin api yang membentang sepanjang Lempeng Pasifik yang merupakan lempeng tektonik paling aktif di dunia. Kementerian Pekerjaan Umum (Kementerian PU, 2010 dan Kementerian PUPR, 2017) telah mengeluarkan Peta Ancaman Bahaya Gempabumi; berdasarkan peta tersebut, Jakarta berada pada zona kegempaan sedang, artinya ada potensi gempa tingkat sedang terjadi di Jakarta. Potensi ancaman akan dikorelasikan menjadi nilai intensitas gempabumi dalam skala MMI (U. S. Geological Survey (2011))

Pusat Teknologi Lahan Wilayah dan Bencana (PTLWB), yang sekarang menjadi Pusat Teknologi Reduksi Risiko Bencana (PTRRB) - Badan Pengkajian dan Penerapan Teknologi (BPPT) (Pradono, 2013a) telah membuat peta PGA (Peak Ground Acceleration) DKI Jakarta dan sekitarnya berdasarkan peta ancaman 2010 dan kondisi kelas tanah lunak dengan level hazard 500 tahun (Probabilitas nilai di atas sama atau terlampaui $10 \%$ dalam 50 tahun). 


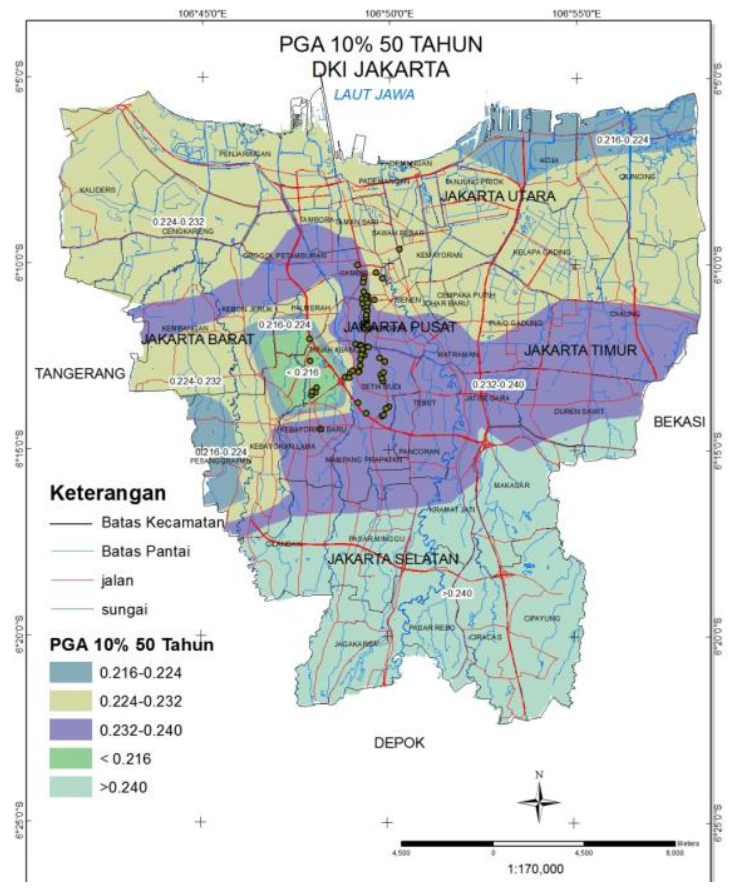

Gambar 1. Peta PGA (Peak Ground Acceleration) di DKI Jakarta dan sekitarnya dengan level hazard 500 tahunan (Sumber: Pradono, 2013a).

Berdasarkan peta (Gambar 1) dan jenis tanah di DKI Jakarta (tanah sedang sampai dengan lunak), maka gedung bertingkat di DKI Jakarta harus kuat terhadap PGA sekitar $0.216-0.240 \mathrm{~g}$ (g adalah percepatan gravitasi). Nilai PGA ini setara dengan skala intensitas gempa MMI VII.

Pada tahun 2015 dan 2016, PTRRB - BPPT juga telah melakukan kaji cepat kerentanan 377 gedung bertingkat di DKI Jakarta dengan 4 (empat) parameter yaitu, tahun pembuatan, bentuk, jumlah lantai dan fungsi gedung. Letak geografis 377 gedung yang dikaji telah di-overlay pada peta tersebut dan juga untuk beberapa skenario intensitas gempabumi dalam satuan MMI (Modified Mercalli Intensity).

Hasil dari kaji kerentanan tersebut digunakan dalam kajian ini sebagai dasar menentukan tingkat kerentanan gedung yang dipilih. Metode pembuatan kurva kerentanan dan hasil-hasilnya dapat dilihat di daftar pustaka (Pradono, 2013b).

Pada tahun 2017 (PTRRB, 2017), PTRRB mengembangkan metode kajian terhadap kapasitas tindak suatu gedung bertingkat terhadap ancaman gempabumi. Kapasitas tindak adalah kapasitas suatu gedung ditinjau dari dua segi: fasilitas dan soft skill. Yang termasuk dalam fasilitas adalah:

- Tangga darurat

- Jalur evakuasi

- Pengamanan barang

- Titik kumpul

- Hidran
Yang termasuk dalam soft skill adalah:

- Pelatihan

- Pengetahuan

Metode sejenis yang dikembangkan adalah VISUS (SPRINT-Lab, 2015). Metode VISUS dalam Bahasa Inggris adalah Visual Inspection for defining the Safety Upgrading Strategies. Dalam bahasa Indonesia dapat diartikan sebagai: Inspeksi Visual untuk mendefinisikan Strategi Peningkatan Keamanan. VISUS pertama kali dikembangkan dengan tujuan untuk menilai sekolah dalam skenario seismik, tetapi kemudian berkembang menjadi pendekatan holistik dan multi-bahaya yang mempertimbangkan lima masalah:

- kondisi lokasi,

- kinerja struktural,

- kekritisan struktural lokal,

- komponen non-struktural, dan

- aspek fungsional.

Setiap masalah akan dianalisis dengan menggunakan pra-kodifikasi penalaran ahli, yang membagi penilaian dalam dua fase utama: karakterisasi dan evaluasi. Sebagai hasilnya, indikator grafis sederhana merangkum evaluasi yang menunjukkan kelemahan utama dan kebutuhan intervensi. VISUS dapat digunakan sebagai alat pengambilan keputusan yang efektif untuk merencanakan tindakan dalam mitigasi risiko pada skala regional setelah pendekatan rasional. VISUS dapat beradaptasi dengan berbagai konteks dan kebutuhan lokal. Metode ini menyediakan sub-produk yang berbeda, seperti transfer pengetahuan ilmiah melalui peningkatan kapasitas insinyur lokal dan pengambil keputusan; aplikasi seluler untuk mengumpulkan data terkait; produksi laporan individu dan kolektif sekolah; dan inventarisasi nasional yang diacu secara geografis dari sekolah-sekolah dalam platform pemetaan.

\subsection{Tujuan}

Melakukan kajian kesiapan, dalam hal ini dikaji dari segi kapasitas tindak 16 gedung dari 377 gedung bertingkat di DKI Jakarta. Keenambelas gedung ini dipilih berdasarkan overlay kelas ancaman bencana gempabumi (PGA) dengan kelas kerentanan. Hasil yang diharapkan adalah berupa informasi tingkat kesiapan gedung dan rekomendasi untuk meningkatkan kesiapannya.

\section{METODA PENELITIAN}

\subsection{Pengumpulan Data}


Pengumpulan data dilakukan pada gedunggedung yang dipilih. Pemilihan gedung didasarkan pada metode purposive sampling. Ada 377 gedung yang didapatkan dari kajian kerentanan pada tahun 2015 (PTLWB, 2015). Gedung-gedung ini didistribusikan pada matriks $3 \times 3$ berdasarkan kelas ancaman dan kerentanan. Dari masingmasing matriks dipilih 2 gedung, sehingga pada kajian ini ada 18 gedung yang akan disurvei. Dari ke-18 gedung, hanya berhasil didapat data primer dari 16 gedung, karena 2 gedung tidak bersedia disurvei. Survei yang dilakukan berupa wawancara dan pengisian kuesioner.

\subsubsection{Pembuatan Kuesioner}

Kuesioner dibuat dengan mempertimbangkan parameter-parameter kapasitas. Dengan mengacu kepada kriteria yang sudah ditetapkan dalam beberapa peraturan (SNI, 2000; BNPB, 2015) ditentukan parameter yang digunakan adalah:

- Tangga darurat, meliputi: jumlah, halangan, dimensi dan bahan

- Hidran, meliputi jenis hidran yang tersedia apakah tipe hidran kota, taman atau hidran ruangan dengan jumlah hidran ruangan.

- Jalur evakuasi, meliputi rambu-rambu yang menunjukkan arah jalur evakuasi

- Titik kumpul, tersedianya rambu titik kumpul, rambu arah ke titik kumpul, kondisi arah menuju titik kumpul apakah bebas dari barang mudah jatuh serta ketersediaan interkom

- Pengamanan barang mudah jatuh yang beresiko melukai

- Pengetahuan, meliputi cara perlindungan diri dan sosialisasi risiko, serta

- Pelatihan dalam keadaan gawat darurat

\subsubsection{Penentuan Bobot}

Penentuan bobot masing-masing parameter dilakukan dengan metode weighted scoring. Dalam metode ini bobot masing-masing parameter diberikan dengan pertimbangan dari para ahli. Masing-masing ahli memberikan saran bobot yang kemudian diinput dalam bentuk matriks $7 \times 7$ (sesuai dengan jumlah parameter). Dari matriks tersebut didapatkan bobot masing-masing parameter.

\subsection{Pengolahan data kuesioner}

Hasil kuesioner diolah dalam analisis matriks. Skor yang dimiliki setiap gedung dinormalkan sehingga skor masing-masing gedung menjadi compareable. Hasil normalisasi skor kemudian dikalikan dengan bobot parameter sehingga diperoleh nilai akhir masing-masing parameter.

\subsection{Analisis Kapasitas}

Analisis kapasitas dimulai dari penentuan kelas kapasitas. Dalam kajian ini, kelas kapasitas gedung dibagi menjadi tiga yaitu kelas tinggi, sedang, dan rendah. Setelah diperoleh kelas kapasitas suatu gedung, kemudian dapat diberikan rekomendasi yang perlu dilakukan gedung untuk meningkatkan kapasitasnya menghadapi gempa bumi.

\section{HASIL}

\subsection{Perhitungan bobot parameter kapasitas gedung-gedung bertingkat di DKI Jakarta terhadap bencana gempabumi}

Sebelum digunakan untuk survei, kuesioner dibagikan kepada para ahli dengan kompetensi di bidang geologi, teknik sipil, dan manajemen kebencanaan, untuk menentukan bobot parameter dan kriteria. Pembobotan dilakukan dengan "Weighted Scoring Method". Parameter yang ditentukan adalah: kondisi tangga darurat, keberadaan jalur evakuasi, pengamanan barang yang mudah jatuh, pelatihan dan pengetahuan tentang gempa bumi, keberadaan titik kumpul dan hidran.

Bobot parameter dihitung berdasarkan jawaban kuesioner para ahli sebanyak sepuluh orang ahli. Hasil pembobotan adalah sebagai berikut.

Tabel 1. Hasil jawaban kuesioner parameter kapasitas

\begin{tabular}{|l|c|c|c|c|c|c|c|c|}
\hline $\begin{array}{l}\text { Nilai/ } \\
\text { Parameter }\end{array}$ & $\mathbf{7}$ & $\mathbf{6}$ & $\mathbf{5}$ & $\mathbf{4}$ & $\mathbf{3}$ & $\mathbf{2}$ & $\mathbf{1}$ & Total \\
\hline $\begin{array}{l}\text { Tangga } \\
\text { Darurat }\end{array}$ & 4 & 0 & 1 & 3 & 1 & 1 & 0 & 10 \\
\hline $\begin{array}{l}\text { Jalur } \\
\text { Evakuasi }\end{array}$ & 1 & 3 & 3 & 1 & 1 & 1 & 0 & 10 \\
\hline $\begin{array}{l}\text { Pengamanan } \\
\text { Barang }\end{array}$ & 0 & 1 & 3 & 2 & 0 & 1 & 3 & 10 \\
\hline Pelatihan & 2 & 3 & 0 & 3 & 0 & 1 & 1 & 10 \\
\hline Pengetahuan & 3 & 1 & 1 & 1 & 2 & 1 & 1 & 10 \\
\hline Titik Kumpul & 0 & 0 & 1 & 0 & 4 & 4 & 1 & 10 \\
\hline Hidran & 0 & 2 & 1 & 0 & 2 & 1 & 4 & 10 \\
\hline & 10 & 10 & 10 & 10 & 10 & 10 & 10 & \\
\hline
\end{tabular}

Dari hasil jawaban kuesioner tersebut di atas, dilakukan rangking dan pembobotan untuk setiap parameter. Hasil nilai rangking dan bobot adalah sebagai berikut:

Masing-masing ahli diberikan satu lembar tabel isian. Ahli menentukan tingkat kepentingan masing-masing parameter dalam urutan ke-7 untuk menunjukkan parameter tersebut penting dan ke-1 untuk menunjukkan parameter tersebut tidak penting. Hasil perankingan dari masing- 
masing ahli kemudian direkap. Dalam penentuan bobot, masing-masing bidang keahlian para ahli juga memiliki bobot yang berbeda. Urutan bobot masing-masing bidang keahlian adalah; bobot 3 untuk teknik sipil, bobot 2 untuk manajemen bencana dan bobot 1 untuk geologi. Dengan demikian, maka pendapat ahli sipil lebih berpengaruh dibanding dengan bobot ahli geologi.

Pada tabel hasil nampak bahwa tangga darurat dan jalur evakuasi merupakan dua aspek yang paling besar pengaruhnya terhadap kapasitas suatu gedung/ bangunan.

Tabel 2. Hasil nilai rangking dan bobot parameter kapasitas

\begin{tabular}{|c|c|l|r|}
\hline $\begin{array}{c}\text { Rang- } \\
\text { king } \\
\text { ke- }\end{array}$ & $\begin{array}{c}\text { Nilai dari } \\
\text { Ahli }\end{array}$ & Parameter & $\begin{array}{c}\% \\
\text { Bobot }\end{array}$ \\
\hline 1 & 7 & $\begin{array}{l}\text { Tangga } \\
\text { darurat }\end{array}$ & 25,00 \\
\hline 2 & 6 & $\begin{array}{l}\text { Jalur } \\
\text { evakuasi }\end{array}$ & 21,43 \\
\hline 3 & 5 & $\begin{array}{l}\text { Pengamanan } \\
\text { barang }\end{array}$ & 17,86 \\
\hline 4 & 4 & Pelatihan & 14,29 \\
\hline 5 & 3 & Pengetahuan & 10,71 \\
\hline 6 & 2 & Titik kumpul & 7,14 \\
\hline 7 & 1 & Hidran & 3,57 \\
\hline & 28 & & 100,00 \\
\hline
\end{tabular}

Dengan demikian, parameter yang paling berpengaruh terhadap kapasitas gedung bertingkat terhadap gempabumi berturut-turut adalah:

- Tangga darurat, dengan bobot 25,00

- Jalur evakuasi, dengan bobot 21,43

- Pengamanan Agar Barang Tidak Jatuh, dengan bobot 17,86

- Pelatihan tentang Gempabumi, dengan bobot 14,29

- Pengetahuan tentang Gempabumi, dengan bobot 10,71

- Titik Kumpul, dengan bobot 7,14

- Hidran, dengan bobot 3,57

\subsection{Perhitungan skor kapasitas gedung- gedung bertingkat terhadap bencana gempa bumi di DKI Jakarta.}

Di bawah ini adalah contoh aplikasi pengisian formulir kapasitas gedung terhadap gempabumi (Tabel 3) yang diberi bobot sesuai perhitungan sebelumnya. Tabel tersebut berisi informasi mengenai:

Nama gedung

- $\quad$ Alamat gedung

- Koordinat gedung
- Nama dan nomor kontak sumber informasi Ada tidaknya parameter/ subparameter Kondisi parameter/subparameter

Tabel 3. Hasil penilaian parameter dan subparameter kapasitas

Tabel XXX Contoh hasil pengisian kuesioner

$\begin{array}{ll}\text { Nama Gedung } & : \mathbf{x x x x x} \\ \text { Alamat } & : \quad \mathbf{x x x x x} \text { Jakarta } \\ \text { Pusat } & : x^{\circ} \mathbf{S}, \mathbf{x x}^{\circ} \mathrm{E} \\ \text { Koordinat } & : \text { Bapak/lbuxxxxxx } \\ \text { Sumber Informasi } & \end{array}$

\begin{tabular}{|c|c|c|c|c|c|c|}
\hline \multirow{3}{*}{$\begin{array}{l}\text { Para- } \\
\text { meter }\end{array}$} & \multirow{3}{*}{ Bobot } & \multirow{3}{*}{ Kriteria } & \multicolumn{3}{|c|}{$\begin{array}{l}\text { Kondisi } \\
\text { Kriteria }\end{array}$} & \multirow{3}{*}{$\begin{array}{l}\text { Nilai } \\
\text { Skor }\end{array}$} \\
\hline & & & \multicolumn{2}{|c|}{ Ada } & \multirow{2}{*}{$\begin{array}{r}\text { Tidak } \\
\text { ada }\end{array}$} & \\
\hline & & & S & TS & & \\
\hline \multirow{4}{*}{$\begin{array}{l}\text { Tangga } \\
\text { Darurat }\end{array}$} & \multirow{4}{*}{25} & Jumlah & $x$ & & & \\
\hline & & \begin{tabular}{|l|} 
Bebas \\
halangan \\
\end{tabular} & $x$ & & & \\
\hline & & Dimensi & $x$ & & & \\
\hline & & Bahan & $x$ & & & \\
\hline \multirow{3}{*}{ Hidran } & \multirow{3}{*}{3.57} & Kota & $x$ & & & \\
\hline & & Taman & $x$ & & & \\
\hline & & Ruangan & $x$ & & & \\
\hline \multirow{2}{*}{$\begin{array}{l}\text { Jalur } \\
\text { evakuasi }\end{array}$} & \multirow{2}{*}{21.43} & Rambu & & $x$ & & \\
\hline & & & $x$ & & & \\
\hline \multirow{4}{*}{$\begin{array}{l}\text { Titik } \\
\text { kumpul }\end{array}$} & \multirow{4}{*}{7.14} & $\begin{array}{l}\text { Rambu } \\
\text { Titik } \\
\text { kumpul }\end{array}$ & $x$ & & & \\
\hline & & $\begin{array}{l}\text { Rambu } \\
\text { arah ke } \\
\text { titik } \\
\text { kumpul }\end{array}$ & & & $x$ & \\
\hline & & $\begin{array}{l}\text { Bebas } \\
\text { dari } \\
\text { barang } \\
\text { mudah } \\
\text { jatuh }\end{array}$ & $x$ & & & \\
\hline & & Interkom & & $\mathrm{x}$ & & \\
\hline $\begin{array}{l}\text { Peng- } \\
\text { amanan } \\
\text { barang } \\
\text { (agar tidak } \\
\text { jatuh) }\end{array}$ & 17.86 & & & $x$ & & \\
\hline \multirow[t]{2}{*}{$\begin{array}{l}\text { Penge- } \\
\text { tahuan }\end{array}$} & \multirow[t]{2}{*}{10.71} & \begin{tabular}{|c|} 
Petunjuk \\
cara \\
perlin- \\
dungan \\
diri \\
\end{tabular} & & & $\mathrm{x}$ & \\
\hline & & Sosialisasi & $x$ & & & \\
\hline \multirow[t]{2}{*}{$\begin{array}{l}\text { Pela- } \\
\text { tihan }\end{array}$} & 14.29 & Pelatihan & $\mathrm{x}$ & & & \\
\hline & & & & & & 8 \\
\hline
\end{tabular}

S : Standart. TS: Tidak Standart

Perhitungan skor masing-masing gedung didasarkan:

- Jika kriteria ada dan memenuhi standar, nilainya $=2$.

- Jika kriteria ada tapi tidak memenuhi standar, nilainya $=1$.

- Jika kriteria tidak ada, nilainya $=0$. 
Rekapitulasi hasil nilai kapasitas total terhadap gempabumi untuk enam belas gedung yang disurvei dapat dilihat pada Tabel 4. Nilai kapasitas total diperoleh dari nilai masing-masing parameter dikalikan dengan bobot parameter (Tabel 6). Bobot total yang termasuk dalam kelas kapasitas rendah adalah $0-0.33$; kelas sedang antara $0.34-0.67$; dan rentang nilai dalam kelas kapasitas tinggi adalah $0.68-1$. Penghitungan untuk menentukan kelas kapasitas dapat dilihat pada Tabel 5.

Tabel 4. Rekapitulasi nilai kapasitas gedung terhadap gempabumi

\begin{tabular}{|l|l|l|c|}
\hline $\begin{array}{c}\text { Kelas } \\
\text { Bahaya }\end{array}$ & $\begin{array}{c}\text { Kelas } \\
\text { Kerentanan }\end{array}$ & \multicolumn{1}{|c|}{$\begin{array}{c}\text { Nama } \\
\text { Gedung }\end{array}$} & $\begin{array}{c}\text { Nilai } \\
\text { Parameter } \\
\text { Kapasitas }\end{array}$ \\
\hline \multirow{4}{*}{ Tinggi } & \multirow{2}{*}{ Tinggi } & $1 . \mathrm{A} 1$ & 29 \\
\cline { 2 - 4 } & Sedang & 2. A2 & 29 \\
\cline { 2 - 4 } & Rendah & 1. B1 & 14 \\
\cline { 2 - 4 } & & 1. C1 & 28 \\
\hline \multirow{2}{*}{ Sedang } & 2. C2 & 17 \\
\cline { 2 - 4 } & Tinggi & $1 . \mathrm{D} 1$ & 23 \\
\hline
\end{tabular}

\begin{tabular}{|c|c|c|c|}
\hline & & 2. D2 & 20 \\
\hline & \multirow{2}{*}{ Sedang } & 1. E1 & 28 \\
\hline & & 2. E2 & 21 \\
\hline & \multirow{2}{*}{ Rendah } & 1. $\mathrm{F} 1$ & 27 \\
\hline & & 2. F2 & 26 \\
\hline \multirow{6}{*}{ Rendah } & \multirow{2}{*}{ Tinggi } & 1. G1 & Tidak ada \\
\hline & & 2. $\mathrm{G} 2$ & 22 \\
\hline & \multirow{2}{*}{ Sedang } & 1. $\mathrm{H} 1$ & 25 \\
\hline & & 2. $\mathrm{H} 2$ & 12 \\
\hline & \multirow{2}{*}{ Rendah } & 1. J1 & 26 \\
\hline & & 2. J2 & Tidak ada \\
\hline
\end{tabular}

Tabel 5. Rentang Bobot Total dalam Penentuan Kelas Kapasitas Gedung terhadap Gempabumi

\begin{tabular}{|l|c|c|}
\hline \multicolumn{3}{|c|}{$\begin{array}{c}\text { Rentang Bobot Total dan Kelas Kapasitas } \\
\text { Gedung Terhadap Gempabumi }\end{array}$} \\
\hline Rendah & 0,00 & 0,33 \\
\hline Sedang & 0,34 & 0,67 \\
\hline Tinggi & 0,68 & 1,00 \\
\hline
\end{tabular}

Tabel 6. Hasil Perhitungan Kelas Kapasitas

\begin{tabular}{|c|c|c|c|c|c|c|c|c|c|}
\hline \multirow{2}{*}{$\begin{array}{c}\text { Nama } \\
\text { Gedung }\end{array}$} & \multicolumn{7}{|c|}{ Bobot Parameter Kapasitas } & Bobot & $\begin{array}{c}\text { Kelas } \\
\text { Kapasitas }\end{array}$ \\
\cline { 2 - 11 } & $\begin{array}{c}\text { Tangga } \\
\text { Darurat }\end{array}$ & $\begin{array}{c}\text { Jalur } \\
\text { Evak. }\end{array}$ & $\begin{array}{c}\text { Pengam. } \\
\text { Barang }\end{array}$ & Pelatihan & $\begin{array}{c}\text { Pengeta } \\
\text {-huan }\end{array}$ & $\begin{array}{c}\text { Titik } \\
\text { Kum } \\
- \text { pul }\end{array}$ & Hidran & Total & Absolut \\
\hline A1 & 0,25 & 0,21 & 0,18 & 0,07 & 0,08 & 0,05 & 0,04 & 0,88 & Tinggi \\
\hline C1 & 0,22 & 0,00 & 0,09 & 0,00 & 0,03 & 0,04 & 0,02 & 0,39 & Sedang \\
\hline C2 & 0,22 & 0,21 & 0,09 & 0,07 & 0,03 & 0,04 & 0,04 & 0,69 & Tinggi \\
\hline D2 & 0,25 & 0,05 & 0,09 & 0,07 & 0,05 & 0,01 & 0,04 & 0,56 & Sedang \\
\hline H2 & 0,13 & 0,00 & 0,00 & 0,07 & 0,00 & 0,01 & 0,04 & 0,24 & Rendah \\
\hline E1 & 0,25 & 0,16 & 0,09 & 0,14 & 0,05 & 0,04 & 0,04 & 0,77 & Tinggi \\
\hline F1 & 0,25 & 0,11 & 0,18 & 0,07 & 0,11 & 0,04 & 0,04 & 0,79 & Tinggi \\
\hline F2 & 0,25 & 0,11 & 0,18 & 0,07 & 0,03 & 0,05 & 0,04 & 0,72 & Tinggi \\
\hline J1 & 0,25 & 0,16 & 0,00 & 0,07 & 0,03 & 0,06 & 0,04 & 0,61 & Sedang \\
\hline B1 & 0,19 & 0,05 & 0,09 & 0,00 & 0,00 & 0,02 & 0,02 & 0,37 & Sedang \\
\hline B2 & 0,25 & 0,11 & 0,09 & 0,14 & 0,08 & 0,05 & 0,04 & 0,76 & Tinggi \\
\hline H1 & 0,25 & 0,21 & 0,18 & 0,07 & 0,03 & 0,04 & 0,02 & 0,81 & Tinggi \\
\hline D1 & 0,22 & 0,11 & 0,09 & 0,07 & 0,05 & 0,04 & 0,04 & 0,62 & Sedang \\
\hline G2 & 0,25 & 0,11 & 0,00 & 0,07 & 0,05 & 0,03 & 0,04 & 0,54 & Sedang \\
\hline E2 & 0,22 & 0,16 & 0,09 & 0,07 & 0,11 & 0,00 & 0,03 & 0,68 & Tinggi \\
\hline B2 & 0,22 & 0,21 & 0,09 & 0,07 & 0,11 & 0,05 & 0,04 & 0,79 & Tinggi \\
\hline
\end{tabular}

\section{PEMBAHASAN}

Hasil perhitungan di atas menunjukkan bahwa:

1. Dari enambelas gedung yang disurvei, sembilan gedung mempunyai kapasitas tinggi, enam gedung kapasitas sedang, dan satu gedung mempunyai kapasitas rendah.

2. Sembilan gedung dinilai memiliki tingkat kapasitas tinggi karena parameter dan kriterianya sudah baik.
Walaupun demikian, masih ada beberapa kriteria dari parameter yang perlu diperhatikan, adalah sebagai berikut:

- Semua gedung yang disurvei ternyata tidak pernah mendapat pelatihan dan sosialisasi tentang gempabumi untuk pengelola serta pengguna gedung. Kesembilan gedung tersebut juga belum memiliki petunjuk cara perlindungan diri terhadap gempabumi misalnya dalam bentuk stiker dan banner atau bentuk lainnya. 
- Perlu diperhatikan pula tentang pengamanan barang yang mudah jatuh, karena hanya satu dari sembilan gedung yang sudah memperhatikan pengamanan barang, antara lain dengan memiliki lemari yang tertanam ke tembok, tidak ada lampu hias gantung ataupun barang pajangan yang besar dan berat yang mungkin dapat melukai manusia bila terlepas ketika terjadi gempabumi.

\section{- Tangga darurat:}

Ada dua dari sembilan gedung yang memiliki tangga darurat belum memenuhi standar. Adapun beberapa syarat SNI untuk tangga darurat antara lain adalah:

- Jumlahnya dua buah bila jumlah penghuni gedung $\leq 500$ orang; jumlah tiga buah bila jumlah penghuni $500 \leq x$ $\leq 1000$ orang; dan berjumlah empat buah apabila jumlah penghuni $\geq 1000$ orang.

- Dimensinya adalah lebar $90-110 \mathrm{~cm}$; anak tangga memiliki tinggi $10-18 \mathrm{~cm}$, minimum kedalaman $28 \mathrm{~cm}$; minimum ketinggian ruangan adalah $200 \mathrm{~cm}$.

Selain itu, dua dari sembilan gedung memiliki tangga darurat yang belum benar penggunaannya, antara lain belum bebas halangan misalkan ada AC yang mungkin bisa jatuh dan menghalangi, masih banyak tangga darurat yang tertutup oleh barang dagangan dan tidak terjaga kebersihannya; lalu ada tangga darurat hanya berupa tangga biasa yang berada di tengah gedung; selain itu bahan tangga darurat tidak memenuhi standar.

- Titik kumpul: kesembilan gedung sudah memiliki rambu titik dan rambu arah, tetapi tidak memiliki rambu titik dan rambu arah yang seragam dikarenakan belum ada SNInya. Selain itu beberapa gedung tidak memiliki pengeras suara/interkom yang mencapai titik kumpul, dan luas titik kumpul relatif kecil dibandingkan jumlah penghuni

- Jalur evakuasi: kesembilan gedung sudah memiliki rambu dan denah evakuasi tetapi rambu jalur dan denah evakuasi tidak jelas dan tidak seragam dikarenakan belum ada SNI mengenai bentuk, warna, ukuran jalur evakuasi.

- Hidran: hampir semua memiliki hidran taman dan apar ruangan, hanya ada satu gedung yang tidak memiliki hidran kota terdekat.

3. Satu gedung memiliki tingkat kapasitas rendah, karena:

a. Tangga darurat: baik jumlah, dimensi, bahan tidak memenuhi standar (SNI), tidak bebas dari halangan, dan tidak terjaga kebersihannya b. Jalur evakuasi: rambu dan denah tidak ada

c. Pengamanan barang: tidak ada

d. Pelatihan: tidak ada pelatihan tentang gempa dan sosialisasinya kepada pengelola gedung

e. Pengetahuan: Belum tahu cara perlindungan diri terhadap gempa

f. Titik kumpul: tidak ada rambu ke arah titik kumpul, tidak mempunyai pengeras suara atau interkom yang mencapai titik kumpul

\section{KESIMPULAN}

Dari hasil kajian, dapat disimpulkan hal-hal sebagai berikut:

1. Kesiapan enambelas gedung bertingkat yang disurvei di DKI Jakarta terhadap bencana gempabumi menunjukkan hasil yang baik, sembilan dari enambelas (57\%) gedung mempunyai kapasitas tinggi, enam (37\%) gedung mempunyai kapasitas sedang, dan hanya satu $(6 \%)$ gedung mempunyai kapasitas rendah.

2. Parameter dan kriteria yang perlu diperhatikan agar suatu gedung memiliki tingkat kapasitas tinggi, antara lain:

a. Tangga darurat: baik jumlah, dimensi, bahan harus memenuhi standar (SNI), harus bebas dari halangan, dan harus terjaga kebersihannya

b. Jalur evakuasi: rambu dan denah harus ada

c. Pengamanan barang: harus ada

d. Pelatihan: harus ada pelatihan tentang gempa dan sosialisasinya kepada pengelola gedung

e. Pengetahuan: harus tahu perlindungan diri terhadap gempa

cara

f. Titik kumpul: harus ada rambu ke arah titik kumpul, harus mempunyai pengeras suara atau interkom yang mencapai titik kumpul.

Secara umum, keenambelas gedung yang disurvei di DKI Jakarta tidak mendapat pelatihan khusus cara perlindungan diri terhadap bencana gempabumi. Seandainyapun ada, pelatihan yang yang diperoleh dan pernah dilakukan terhadap bencana hanya mengenai kebakaran. Oleh karena itu, rekomendasi yang dapat diberikan adalah sebagai berikut:

1. BPBD (Badan Penanggulangan Bencana Daerah) perlu mengadakan pelatihan, sosialisasi, dan gladi terhadap pengelola gedung sehingga pengelola dan pengguna gedung tahu apa yang harus dilakukan ketika gempabumi, pada saat terjadi dan setelah kejadian.

2. Selain untuk pengelola dan pengguna gedung, sosialisasi dapat pula diberikan 
untuk masyarakat luas melalui media sosial, buku-buku pelajaran sekolah, dan posterposter yang mudah diproduksi ulang, mengenai bahan-bahan pengetahuan umum untuk persiapan dan penyelamatan diri dari bencana gempabumi. Untuk itu BPBD dapat bekerja sama dengan Kemkominfo (Kementerian Komunikasi dan Informatika) dan Kemenristekdikti.

3. Perlu juga penyiapan standar oleh Kementerian PUPR (Kementerian Pekerjaan Umum dan Perumahan Rakyat) dan kemudian sosialisasi oleh BPBD mengenai SNI tentang tangga darurat, rambu dan denah jalur evakuasi, rambu dan denah titik kumpul, sehingga ada keseragaman dalam bentuk, warna dan ukuran.

4. BPBD juga perlu membuat aturan tentang cara pengamanan barang yang dapat menimpa orang, dan lain sebagainya, yang berguna sebagai pengetahuan untuk pengelola dan pengguna gedung mengenai perlindungan diri terhadap bencana gempabumi.

\section{DAFTAR PUSTAKA}

BNPB (2015) Rambu dan Papan Informasi Bencana Perka BNPB 07 2015, Badan Nasional Penanggulangan Bencana.

Kementerian Pekerjaan Umum (2010) Peta Hazard Gempa Indonesia 2010.

Kementerian Pekerjaan Umum dan Perumahan Rakyat (2017) Peta Sumber dan Bahaya Gempa Indonesia Tahun 2017. Tim Pusat Studi Gempa Nasional.

Pradono, M.H. (2013 a) "Intensitas Gempabumi DKI Jakarta Berdasarkan Peta Hazard Gempa Indonesia 2010" Jurnal Sains dan Teknologi Mitigasi Bencana, Vol. 8, No. 2, Tahun 2013.

Pradono, M.H. (2013 b) "Kerentanan Gedung di DKI Jakarta terhadap Ancaman Gempabumi" Jurnal Sains dan Teknologi Mitigasi Bencana, Vol. 8, No. 2, Tahun 2013.

PTLWB (2015) Technical Document, Tahap III Critical Program Review No. TD 3 / MHP / WBS-4 / PPTRRB / 2015, WBS 4 Pilot Plan Teknologi EQ Ready Building, Pusat Teknologi Pengelolaan Lahan Kawasan dan Mitigasi Bencana (PTLWB), TPSA, BPPT.

PTRRB (2017) Program Manual 2017 Inovasi Teknologi Pengurangan Risiko, Bencana Longsor dan Gempa Bumi, Pengkajian dan Penerapan Teknologi Reduksi Risiko Bencana,
Pusat Teknologi Reduksi Risiko Bencana, TPSA, BPPT.

SNI 03 - 1746 - 2000 (2000) Tata cara perencanaan dan pemasangan sarana jalan ke luar untuk penyelamatan terhadap bahaya kebakaran pada bangunan gedung.

SPRINT-Lab (2015) VISUS Methodology: A Quick Assessment for Defining Safety Upgrading Strategies of School Facilities, SPRINT-Lab researchers of the University of Udine in Italy.

U. S. Geological Survey (2011) ShakeMap Scientific Background. Rapid Instrumental Intensity Maps. Earthquake Hazards Program. Archived from the original on 23 June 2011. Retrieved 22 March 2011. 